Supplementary Material for

\title{
A Novel Approach Through the Harmonized Sulfur in Disordered Carbon Structure for High- Efficiency Sodium-Ion Exchange
}

Hanvin Kim, ${ }^{\dagger},{ }^{*}$ Dae-Yeong Kim, ${ }^{\S}$ Shungo Zen, ${ }^{\dagger}$ Jun Kang ${ }^{\S},{ }^{*}$ and Nozomi Takeuchi ${ }^{\dagger}, *$

+ Department of Electrical and Electronic Engineering, Tokyo Institute of Technology, 2-12-1 Ookayama, Meguro-ku, Tokyo 152-8550, Japan

$\S$ Division of Marine Engineering, Korea Maritime and Ocean University, 727 Taejong-ro, Yeongdogu, Busan 49112, Korea

* Corresponding authors: kim.h.av@m.titech.ac.jp (Hanvin Kim); junkang@kmou.ac.kr (Jun Kang); takeuchi@ee.e.titech.ac.jp (Nozomi Takeuchi). 


\section{Contents:}

Figure S1. SEM image of $\mathrm{S}_{\mathrm{T}} \mathrm{C}-\mathrm{P}$.

Figure S2. TGA graph of $\mathrm{S}_{\mathrm{T}} \mathrm{C}-\mathrm{P}$.

Figure S3. Galvanostatic charge/discharge curves at various specific currents ranging from 1 to $100 \mathrm{~A}$ $\mathrm{g}^{-1}$.

Figure S4. (a) TEM images of $\mathrm{S}_{\mathrm{T}} \mathrm{C}-\mathrm{P}$ with no SEI layer observed after 100 cycles in the repeated study. (b) Formation of the SEI layer of carbon black synthesized by the plasma-in-liquid process for sodium-ion battery. 


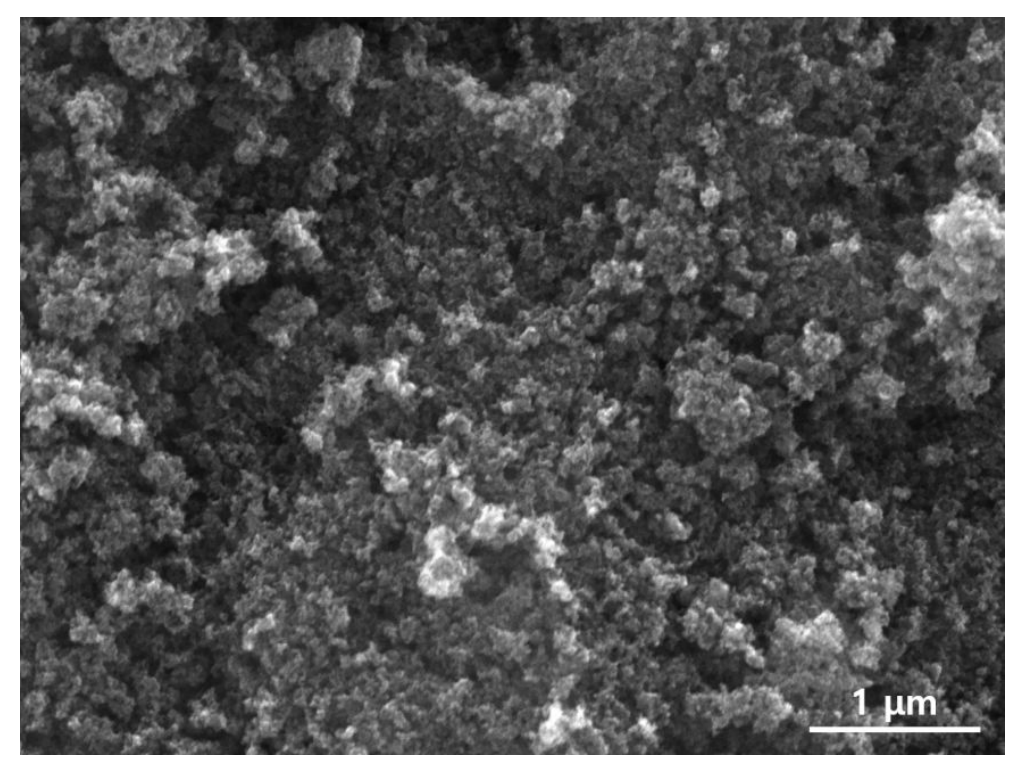

Figure S1. SEM image of $\mathrm{S}_{\mathrm{T}} \mathrm{C}-\mathrm{P}$. 


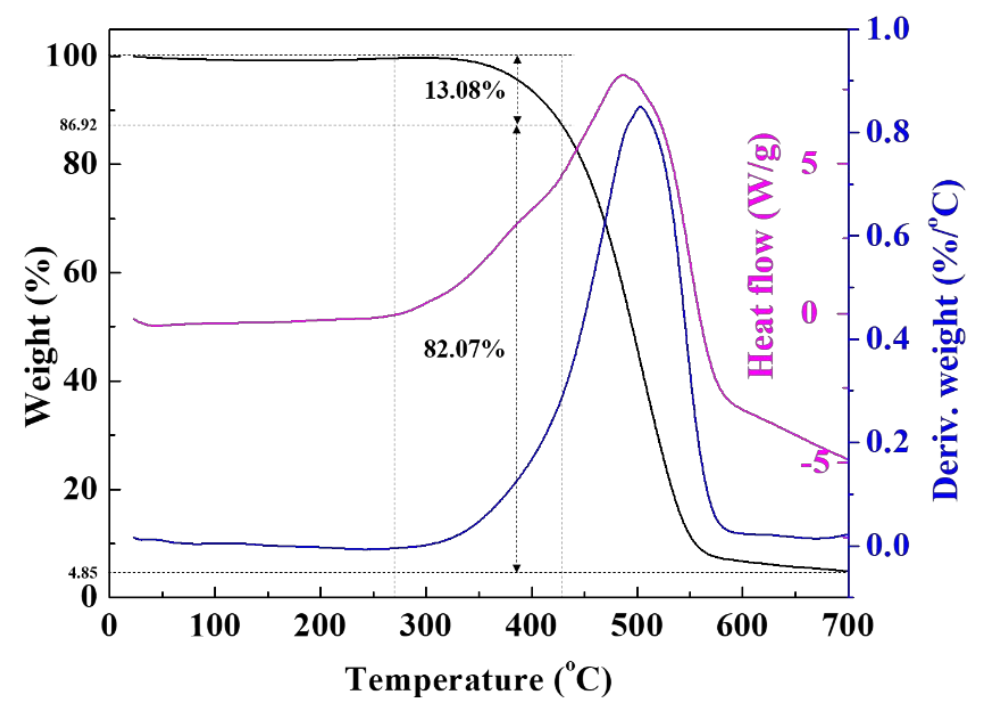

Figure S2. TGA graph of $\mathrm{S}_{\mathrm{T}} \mathrm{C}-\mathrm{P}$.

TGA measurement was performed to quantify the amount of sulfur and carbon components from 10 $700{ }^{\circ} \mathrm{C}$ at a rate of $10^{\circ} \mathrm{C} / \mathrm{min}$. in air. The sulfur component was considered to be burned in a range of $270-430{ }^{\circ} \mathrm{C}$ and the weight loss at this stage was approximately $13.08 \%$. Subsequently, the carbon component was rapidly oxidized up to approximately $550{ }^{\circ} \mathrm{C}$ and gradually reduced to approximately $700{ }^{\circ} \mathrm{C}$. The weight loss in this stage was approximately $82.07 \%$, which was consistent with the EA measurements. ${ }^{1-2}$ The TEM and XPS results imply that the oxygen component was mainly adsorbed on the surface when exposed to the atmosphere. The complete blocking of air into the plasma synthesis process supplements this argument.

[1] Wang, J.; Lu, L.; Shi, D.; Tandiono, R.; Wang, Z.; Konstantinov, K.; Liu, H. A Conductive Polypyrrole-Coated, Sulfur-Carbon Nanotube Composite for Use in Lithium-Sulfur Batteries. ChemPlusChem 2013, 78 (4), 318-324.

[2] Wang, J.-Z.; Lu, L.; Choucair, M.; Stride, J. A.; Xu, X.; Liu, H.-K. Sulfur-graphene composite for rechargeable lithium batteries. Journal of Power Sources 2011, 196 (16), 7030-7034. 


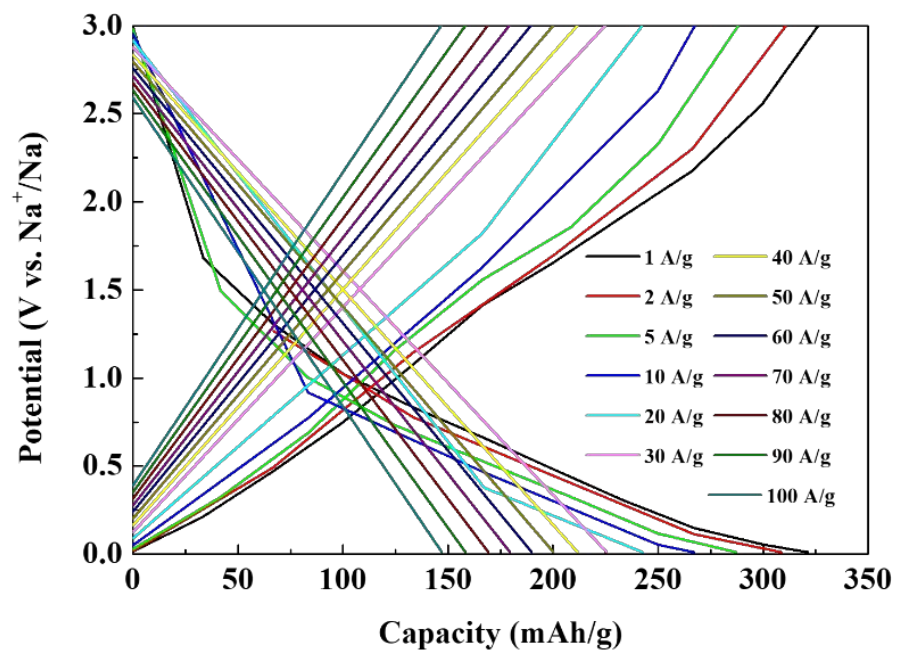

Figure S3. Galvanostatic charge/discharge curves at various specific currents ranging from 1 to $100 \mathrm{~A}$ $\mathrm{g}^{-1}$. 

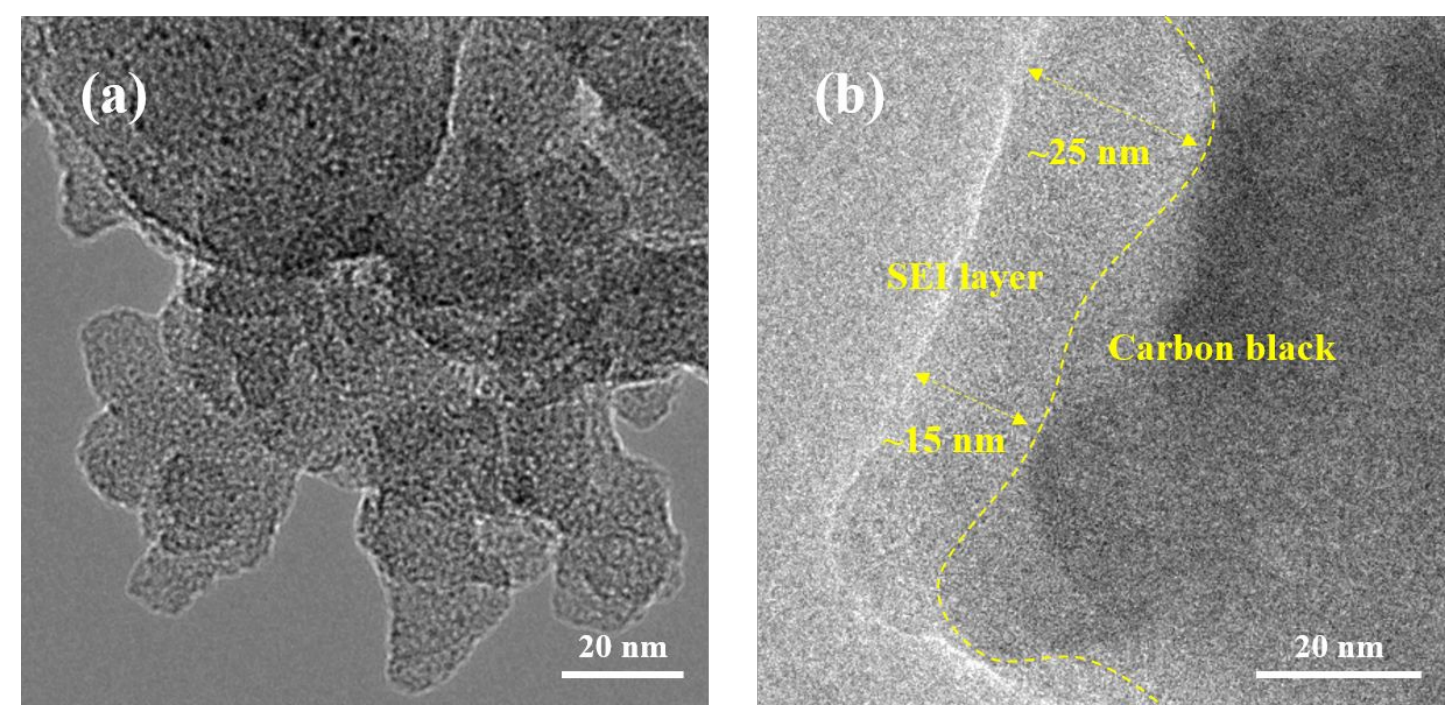

Figure S4. (a) TEM images of $\mathrm{S}_{\mathrm{T}} \mathrm{C}-\mathrm{P}$ with no SEI layer observed after 100 cycles in the repeated study. (b) Formation of the SEI layer of carbon black synthesized by the plasma-in-liquid process for sodium-ion battery. 